\title{
Optimization on Automobile Manufacturing Enterprises Based on Virtual Inventory Management
}

\author{
Du Juan, Liu Lei \\ School of Economics and Management \\ Changchun University of Technology \\ Changchun, China \\ dj737@sohu.com; jymm0603@sohu.com
}

Keywords: Automobile manufacturing enterprises ;Virtual Inventory Management;Technology of the internet of things; Supply chain

\begin{abstract}
Inventory management is the basis for automobile manufacturing enterprises normal production and marketing.At present,Automobile manufacturing enterprises inventory management the main bottleneck is caused by the low level of information technology.From the perspective of supply chain,Application of collaborative management theory and method the technology of the internet of things,establishing a virtual warehouse,Achieve improved enterprises inventory situation and enhance core competitiveness, improve the status of the industry's purpose.
\end{abstract}

\section{Introduction}

In recent years, the rapid development of the automotive industry, production and sales volume rapid growth. Figs. 1 and 2 can be seen from the beginning of 2009 automobile production, sales quantity increased significantly.2009 production growth of $49 \%$, sales growth of $46 \%, 2010-2013$, production growth rate of $28 \%, 5.9 \%, 8.3 \%, 16.6 \%$, sales growth was $32.4 \%, 2.5 \%, 4.3 \%, 14 \%$, The automotive market steady progress.In such mass production, high demand environment, to automobile manufacturers enormous pressure.How to guarantee the normal operation of production to meet market demand, enhance their competitiveness and to occupy a larger market share problem faced by each automobile manufacturing enterprises.Therefore, a high level of inventory management in the automobile manufacturing enterprises is particularly important.

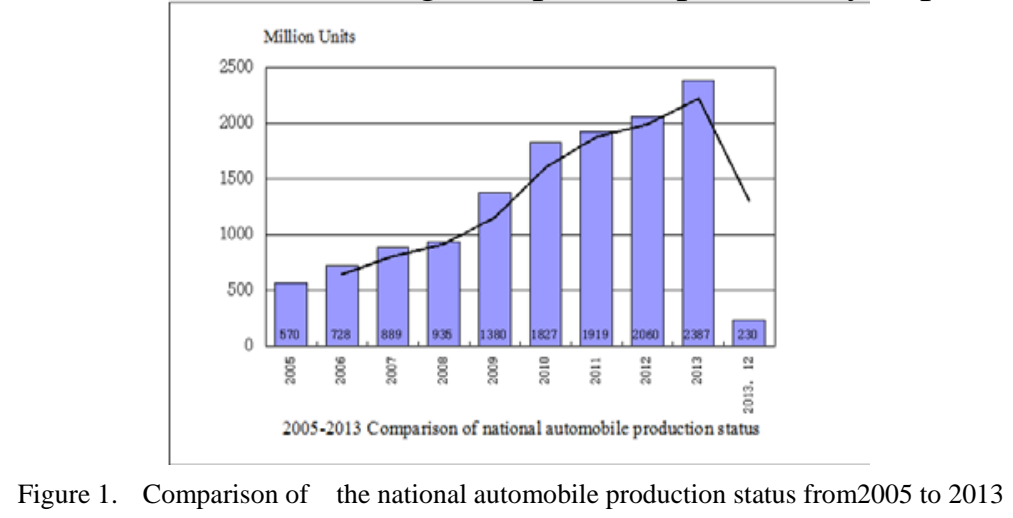




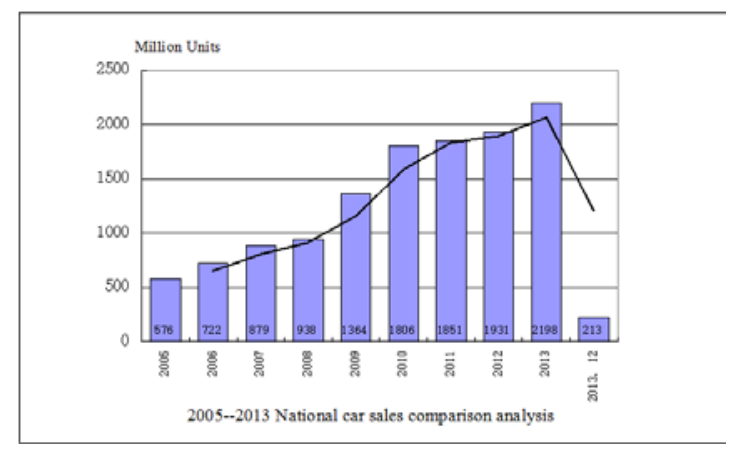

Figure 2. National car sales comparison analysis from 2005 to 2013

In this paper, the optimization of the automobile manufacturing enterprises inventory management is not to achieve so called zero inventory.Most of zero inventory of the enterprise through the stock transferred to the upstream suppliers. The enterprises inventories fell, but the inventory on the whole chain still exists.Just inventory risk transfer to other companies.Measures proposed in this paper is considered from the perspective of the supply chain.By establishing a virtual warehouse to solve the problem of inventory management, not only reduce this manufacturer inventory but also optimize the supply chain inventory management.Extend from the perspective of improving the competitiveness of The manufacturer to improve the competitiveness of the supply chain, in order to improve market position.

\section{Automobile Manufacturing Enterprises Inventory Management Problem Analysis}

\section{Supply Chain Information Flow does not Effectively use}

Figure3. Automobile manufacturing enterprises have complex production processes, a wide variety of materials.According to the characteristics, Assessment of suppliers and Considering the overall interests,Procurement of raw materials and components require different suppliers.Thus, producing a corresponding number of manufacturing enterprises suppliers, each supplier has a corresponding plurality of automobile manufacturing companies.Many to many relationship produced a huge data information,If take advantage of these data information effectively, it will help Optimization on the entire supply chain and each Automobile manufacturing enterprises Inventory.Automobile manufacturing Enterprises can use the master information, re-evaluate and select suppliers, stockpiling the lack of material resources, to ensure complete the production plans.Each node enterprises of supply chain is not fully aware of the huge benefits brought by the flow of information.At the same time the current application of inventory management and information technology is not able to effectively integrate these information resources and sharing.

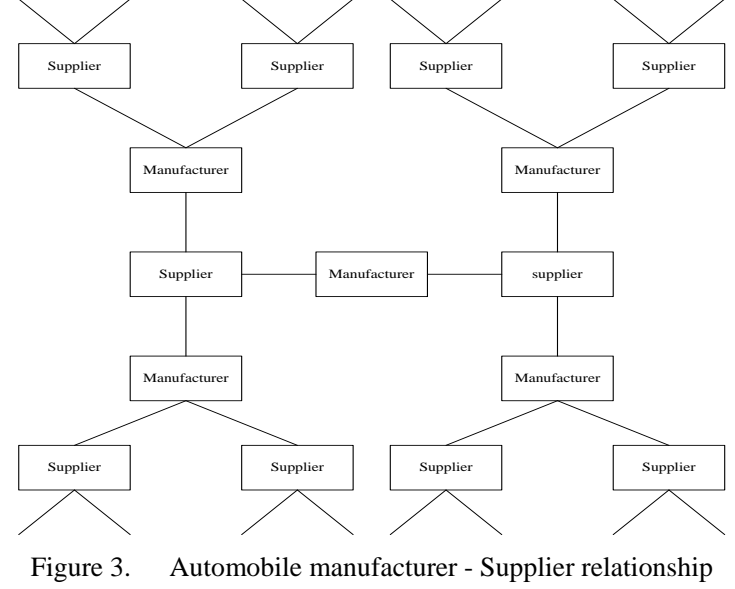

The Inventory of Supply Chain do not Effectively use

One manufacturer corresponds to multiple suppliers and a supplier may have multiple clients.Each member companies have some inventory on the whole supply chain.In order to meet the present enterprises demand and production conditions, there are still a part of inventory, 
management and funding of the occupation of this part of the inventory of the enterprise is a loss.If this part of the inventory circulate within the supply chain can not only strengthen cooperative relations among member enterprises, but also can reduce inventory costs.

\section{Establishing Virtual Warehouse}

As in the automotive manufacturing enterprises inventory management model he Internet is widely used, between the enterprises formed supply chain,the development of modern technology has made virtual inventory management possible.Computer-based, the use of remote monitoring technology,Different geographical locations unified inventory management, scheduling,Information management instead of object management.Dynamic inventory management, flow of commerce separation,Not only to achieve enterprises information sharing, but also sharing resources among enterprises.Through the rational allocation of resources to reduce supply chain uncertainty, implement automobile manufacturing enterprises inventory rationalization

Virtual inventory

Virtual inventory build among the member enterprises,trust 、mutual benefit information sharing, collaborative culture of open communication elements. The use of computer technology and network communication technology, supply chain member companies will contribute a portion of inventory to form a virtual inventory. This part of the warehouse inventory not established entity warehouse, physical inventory is still stored in different locations of the members of the enterprises warehouse.Integration of different geographic locations, different ownership of the physical inventory, unified management and scheduling, rapid response to the changing needs of customers.To expand the available amount of material to the lowest cost.

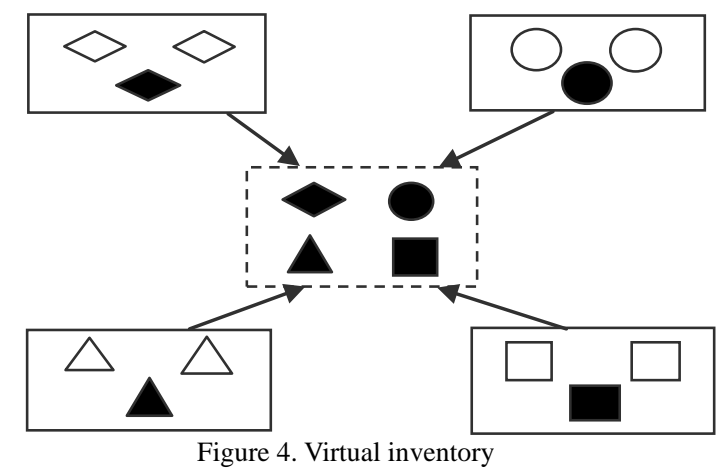

Figure 4 A, B, C, D are four member companies,every enterprise providing a portion of inventory as a virtual warehouse inventory.Still kept the physical inventory by the provides enterprise.Virtual inventory can also be understood as a kind of virtual inventory in the form of information.Virtual inventory can be used as the circulation of commodities, lending, trading, flexible use, improve the overall operational efficiency of the supply chain.

Virtual inventory Cloud Application Platforms

To achieve inventory optimization automotive manufacturers, the most important is the combination of marketing, facility, the information flow generated by suppliers, forming the entire information delivery system that can be monitored.Virtual inventory cloud platforms build by enterprises cloud platforms of a third party or supply chain core manufacturing enterprises.According to each enterprise in the supply chain signing of the agreement would require data information share to the platform.Each supply chain enterprises can log and inquiries through the Password.Virtual inventory cloud platforms mainly provide three pieces of information,Members of the business inventory information, material inventory information, information distribution network.The use of Geographic Information System technology, vendor location, warehouse location, manufacturing location, factory location in real-time to reflect on the electronic map.In the virtual inventory cloud platform, the system automatically plan the optimal path.Member companies ordering on demand,Global Positioning System real-time monitoring of transport condition of the vehicle.The use of cloud technology platform for maintenance and information processing.To establish a virtual inventory cloud platforms, each member of the supply chain closely linked, optimize the supply chain operational efficiency. 
The application of Virtual inventory

Figure5. In the virtual inventory management, supply chain member enterprises through the cloud platform know each other inventory status.Suppliers at any time check various manufacturing order information, inventory. When demand amplification suppliers can borrow virtual warehouse inventory to complete orders.Automobile manufacturing companies according to the suppliers to provide raw materials prices、 quality, speed of delivery, guarantee conditions and other information to make the best purchase plan.But also to grasp the entire raw materials, components market inventory status.According to the agreement signed by the members of the enterprise, companies can borrow free of charge virtual inventory of other members. And more than a certain amount, paid rental inventory.Virtual inventory management in favor of balance between production and supply chain enterprises,Avoiding use excessive funds.It makes automotive manufacturing companies to some extent to reduce inventory management and maintenance costs, and strengthen cooperative relations between enterprises.

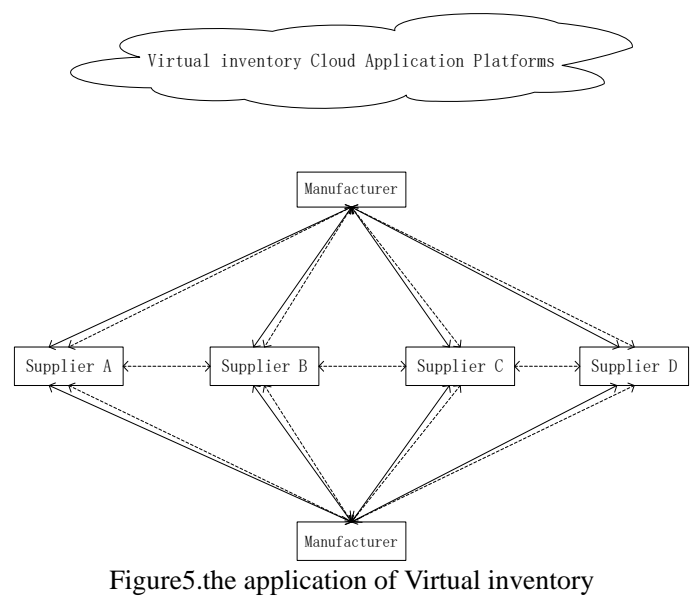

Formal Model of Virtual inventory

In the virtual inventory management, supply chain members make virtual inventory suppliers, automotive manufacturers as a whole.Formal Model of Virtual inventory can be described as:

$\mathrm{Z}$ as a virtual inventory.

$\mathrm{X}$ as Suppliers status (a, b, c, $\mathrm{d}$ as the virtual inventory management suppliers).

$\mathrm{Y}$ as automobile manufacturing node status.

$I_{i}=\left(S_{i-1}, R_{i}\right)$ the input of Suppliers:The external member firms supply the supplier node,the need of Supplier nodes for external member firms.

$O_{\mathrm{i}}=\left(S_{\mathrm{i}}, R_{\mathrm{i}+1}\right)$ the output of Suppliers:The external members of enterprise requirements to suppliers nodes,Number of suppliers supply for the external member firms.

Formal Model of Virtual inventory is $Z=\left(I, O, X_{i}, Y\right)$

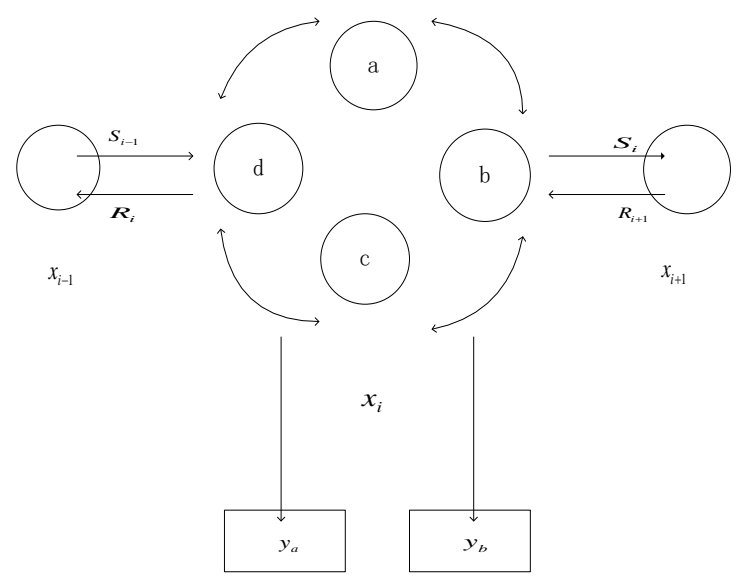

Figure 6. Formal Model of Virtual inventory 
$\mathrm{X}$ represents suppliers, $\mathrm{Y}$ representatives of automotive manufacturers. $X_{\mathrm{i}}$ is a node by consisting of virtual inventory management supplier a, b, c, d. $X_{\mathrm{i}-1}$ is upstream suppliers , $X_{\mathrm{i}+1}$ is this supplier node downstream suppliers. $X_{\mathrm{i}}$ and $\mathrm{Y}$ are the member of Virtual inventory enterprises,As a whole.It can be traded between suppliers and automobile manufacturing enterprises, between suppliers and supplier of member enterprises (a、b、c、d), can also perform a certain number of paid or unpaid loan under the agreement, Through the virtual inventory system, according to stock status, distance and other factors.Supplier of transactions may be performed with an external member enterprises.Supplier requirements and supply for The external member enterprises will affect the virtual inventory levels. So the Formal Model of Virtual inventory is $Z=\left(I, O, X_{i}, Y\right)=\left(S_{i-1}, S_{i}, R_{i}, R_{i+1}, X_{i}, Y_{a}, Y_{b}\right)$

For manufacturing enterprises, want to optimize this enterprise inventory, should start from the perspective of the supply chain.Through effective use of information flow to optimize inventory levels,Information flow at the core of the virtual inventory was in line with the needs of manufacturing companies.By establishing a virtual inventory, both can take advantage of inventory among the members, while avoiding the waste of resources. At the same time, while reducing enterprises inventory, optimizing supply chain inventory levels.And not because of reduced inventory levels of the enterprise, while the inventory risk transfer to other companies.Now the competition, the competition among enterprises has rising the competition between supply chains.Only consider the enterprise inventory situation is not enough, should be combined with inventory supply chain upstream and downstream enterprises to optimize inventories the whole supply chain, in order to improve competitiveness.

\section{Conclusion}

The optimization on Automobile manufacturers inventories management essence is to optimize the flow of information and efficient use.By improving Automobile manufacturers inventory management, to optimize supply chain inventory levels.By using virtual inventory management model based Internet of Things technology, making the physical inventory to virtual information.Application of virtual inventory can fully grasp the inventories dynamics. Entity Inventory management through the management of information, to achieve the purpose of lower inventories management costs ,enhance the competitiveness of enterprises,and improve the development of the whole industry.

\section{Acknowledgment}

I would like to express my gratitude to all those who had helped me during the writing of this thesis. My deepest gratitude goes to professor Du Juan who pr ovide me with a lot of useful suggestions, incisive comments and constructive criticism.Professor D $\mathrm{u}$ devotes a considerable portion of time throughout my preparation of this thesis. Without her cons tant encouragement,patient instruction, insightful criticism and expert guidance.The completion of $t$ his paper would be far more difficult.

Secondly. I would like to express my heartfelt gratitude to my school-Changchun university of technology, which provides such a great atmosphere that influe nces me a lot.It enables us to learn the basic methods of scientific research and lay a solid professio nal foundation.

Last but not least, I would like to show gratitude to my beloved family, for their considerate con sideration and encouragement all through these years.

\section{References}

[1] Harry K.H. Chow, King Lun Choy, W.B. Lee, et al. Design of a RFID case-based resource management system for warehouse operations [J]. Expert Systems with Applications, 2006, 30(4): 561-576. 
[2] Bin Ding, Li Chen, Dianlong Chen, et al. Application of RTLS in Warehouse Management Based on RFID and Wi-Fi [C]. 2008 International Conference on Wireless Communications.

[3] C.C. Røstad, O. Myklebust, B. Moseng. Closing the product lifecycle information loops [C]. Proceedings of 18th International Conference on Production Research, Italy, 2005.

[4] Kenneth T.C.Poon, K.L. Choy, Henry C.W.Lau. A Real-time Manufacturing Risk Management System: An Integrated RFID Approach [C]. Portland International Conference on Management of Engineering and Technology , Portland, OR, United states, 2007: 2872-2879.

[5] Xia nan Qiang, Li Qian, Chen Ming.Collaborative commerce chain design based on cloud computing network[J].Information Science. 2012(07)

[6] Shouqin Zhou, Weiqing Ling, Zhongxiao Peng. An RFID-based remote monitoring system for enterprise internal production management [J]. International Journal of Advanced Manufacturing Technology, 2007, 33(7-8): 837-844.

[7] Shao Ju Ping, Ma Tian yun, Dong Shao Hua.Uncertain environment logistics supply chain integration design models and methods[M].Bei Jing:Economic Science Press, 2010

[8] Kaushik Subramanian,James B.Rawlings,Christors T.Maravalias,Economic model predictive control for inventory management in supply chains,Computers and Chemial Engineering 64(2014)71-80.

[9] Simpson N C.Central versus local multiple stsge inventory planning : an analysis of solutions.European Journal of Operational Research,2007,181(1)127-138

[10] Yang zi Nan.Research on inventory and transportation integrated optimization based on Virtual inventory management[D].Bei Jing:Beijing Jiaotong University 